\title{
Esophageal stricture caused by a mediastinal hamartoma invading the esophageal wall
}

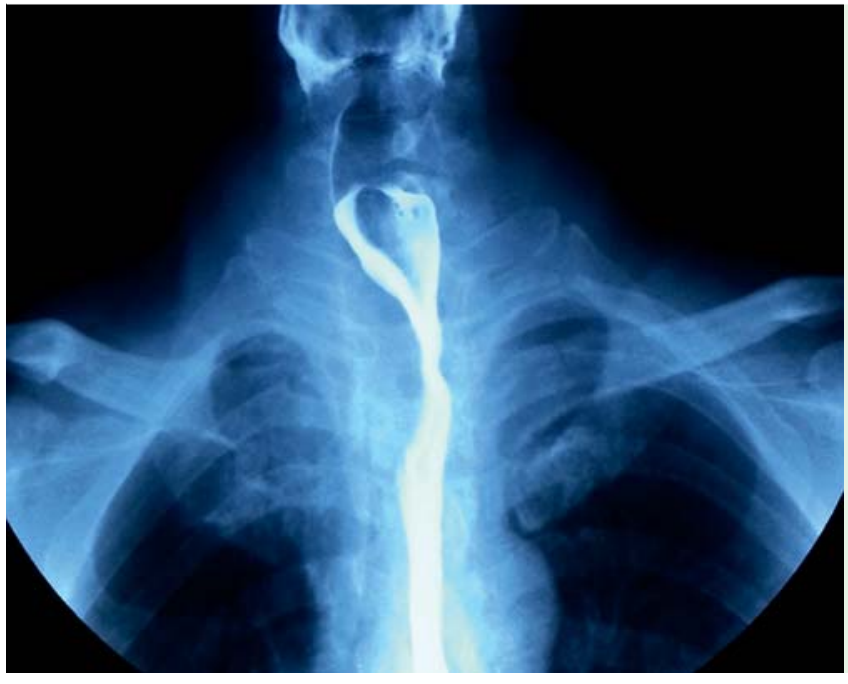

Fig. 1 An esophageal stricture located in his upper esophagus, and smooth mucosa at the narrow segment of the esophagus.

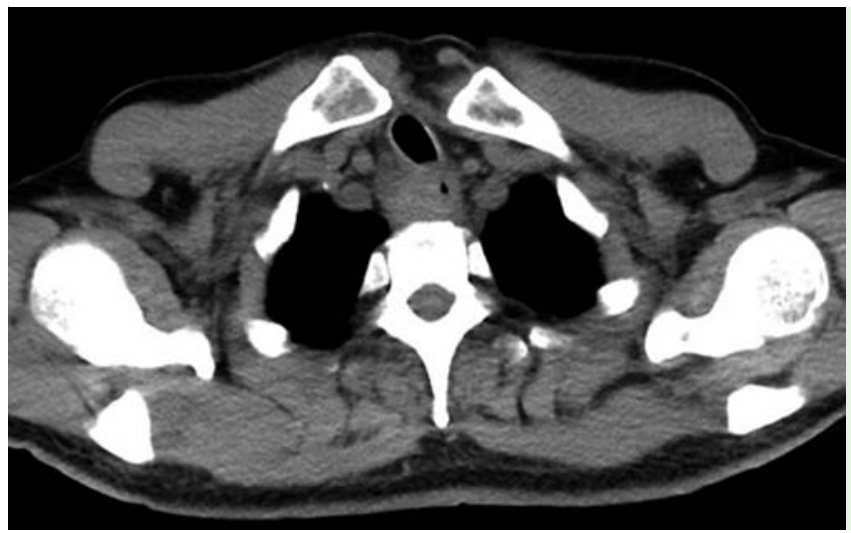

Fig. 3 Computed tomography showed thickening of the mucosa at the upper esophagus.

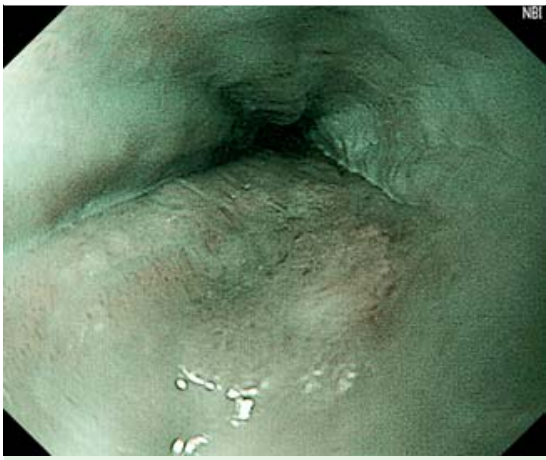

Fig. 2 Narrow-band imaging did not show any abnormality of the mucosal surface.

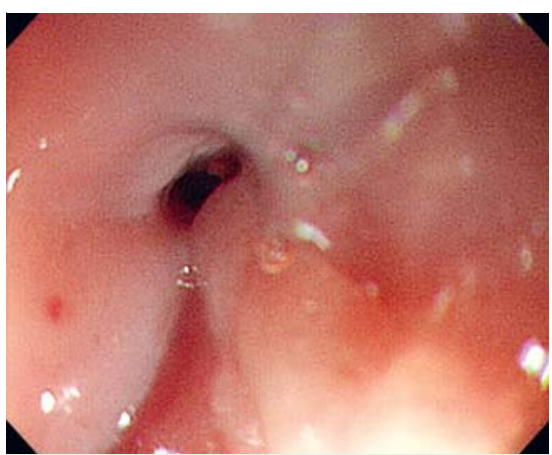

Fig. 4 The esophageal stricture interfered with the insertion of the endoscope.

subtotal resection were performed. Postoperative histopathological examination of the upper esophagus tissues showed the presence of chronic inflammation in the mucosa, squamous epithelial hyperplasia, and chronic suppurative inflammation of the subepithelial focal lesion. Examination of the paraesophageal tumor showed proliferation of tissues including fibers, blood vessels, lymphatic and striated muscles, and nerves with hamartoma-like changes, associated with local inflammatory cell infiltration, degeneration, and necrosis ( $\bullet$ Fig. 6 ).

Hamartomas rarely occur in the esophagus. In this case, the tumor was externally located but had invaded the esophageal wall, which manifested as an esophageal stricture, thereby precluding a diagnosis before surgical operation. and chest computed tomography showed thickening of the mucosa at the upper esophagus ( $\bullet$ Fig.3).

After 4 weeks, the patient underwent a nation On this occasion, an esophagea stricture was observed, which interfered with the insertion of the endoscope. In (- Fig 4). Ultrasound examinatior vealed an obvious thickening of the mucosal layer of the lesion, which appeared asymmetrically annular. There was an unclear boundary between the local and surrounding tissues ( $\bullet$ Fig. 5 ).

Open surgery was performed because the patient experienced a gradual worsening of dysphagia symptoms. During surgery, a tumor was observed between the esophagus and the trachea, which invaded the esophageal wall and had unclear boundaries with the trachea. Because the possibility of a malignant tumor could not be ruled out, esophagus detachment and 

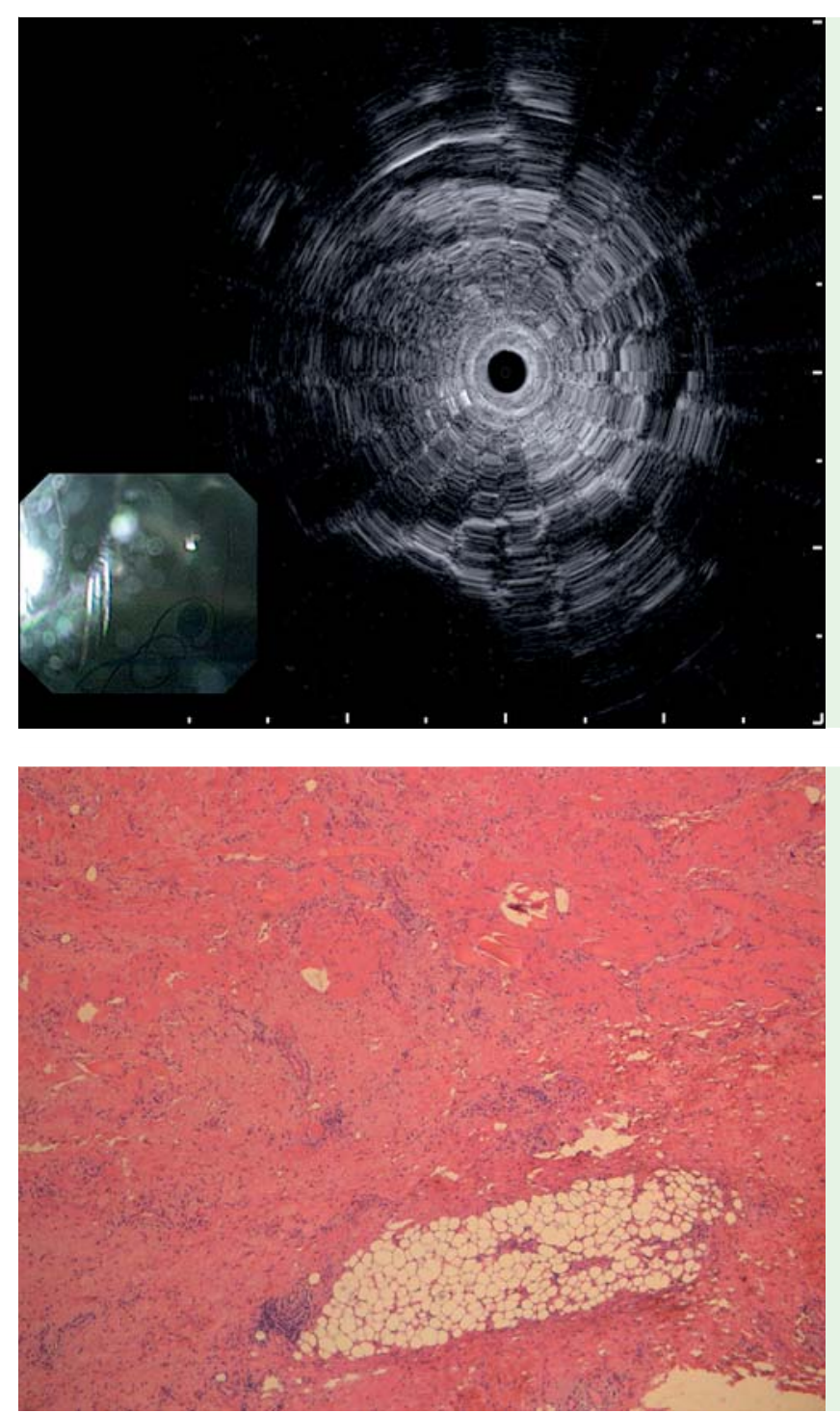
lymphatic and striated
Fig. 5 Endoscopic ultrasound revealed an obvious thickening of the mucosal layer of the lesion.

Endoscopy_UCTN_Code_CCL_1AB_2AC_3AB

\section{Competing interests: None}

\section{Xiao-jun Zhao, Hui Xie, Dong-liang Yu, Jian-qiu Sheng}

Department of Gastroenterology, Beijing Military General Hospital, Beijing, China

\section{Bibliography}

DoI http://dx.doi.org/

10.1055/s-0034-1377533

Endoscopy 2015; 47: E151-E152

(c) Georg Thieme Verlag KG

Stuttgart · New York

ISSN 0013-726X

\section{Corresponding author \\ Jian-qiu Sheng, MS}

Fig. 6 Proliferation of tissues including fibers, blood vessels, muscles, and nerves with hamartoma-like changes.
Department of Gastroenterology Beijing Military General Hospital

Nanmencang 5\#

Dongcheng District

Beijing 100700

China

Fax: +86-10-66721299

jianqiu@263.net 